\author{
Marquette University \\ e-Publications@Marquette
}

3-2006

\title{
Flammability of styrenic polymer clay nanocomposites based on a methyl methacrylate oligomerically-modified clay
}

Xiaoxia Zheng

Marquette University

David D. Jiang

Marquette University

Dongyan Wang

Marquette University

Charles A. Wilkie

Marquette University, charles.wilkie@marquette.edu

Follow this and additional works at: https://epublications.marquette.edu/chem_fac

Part of the Chemistry Commons

\section{Recommended Citation}

Zheng, Xiaoxia; Jiang, David D.; Wang, Dongyan; and Wilkie, Charles A., "Flammability of styrenic polymer clay nanocomposites based on a methyl methacrylate oligomerically-modified clay" (2006). Chemistry Faculty Research and Publications. 107.

https://epublications.marquette.edu/chem_fac/107 
Marquette University

e-Publications@Marquette

\title{
Chemistry Faculty Research and Publications/College of Arts and Sciences
}

This paper is NOT THE PUBLISHED VERSION; but the author's final, peer-reviewed manuscript. The published version may be accessed by following the link in th citation below.

Polymer Degradataion and Stability, Vol. 91, No. 2 (February 2006): 289-297. DOI. This article is (C) Elsevier and permission has been granted for this version to appear in e-Publications@Marquette. Elsevier does not grant permission for this article to be further copied/distributed or hosted elsewhere without the express permission from Elsevier.

\section{Flammability of Styrenic Polymer Clay Nanocomposites Based on A Methyl Methacrylate Oligomerically-Modified Clay}

\author{
Xiaoxia Zheng \\ Department of Chemistry, Marquette University, Milwaukee, WI \\ David D. Jiang \\ Department of Chemistry, Marquette University, Milwaukee, WI \\ Dongyan Wang \\ Department of Chemistry, Marquette University, Milwaukee, WI \\ Charles A. Wilkie \\ Department of Chemistry, Marquette University, Milwaukee, WI
}

\begin{abstract}
Nanocomposites of polystyrene, high impact polystyrene, acrylonitrile-butadiene-styrene terpolymer, polypropylene, and polyethylene were prepared using a methyl methacrylate oligomerically-modified clay by melt blending and the thermal stability and fire retardancy were studied. These nanocomposites were characterized by X-ray diffraction, transmission electron microscopy, thermogravimetric analysis and cone calorimetry. The results show a mixed morphology, depending on the polymer.
\end{abstract}




\section{Keywords}

Fire retardancy, Nanocomposites, Oligomerically-modified

\section{Introduction}

Polymer clay nanocomposite formation enhances the permeability, heat distortion temperature, fire retardancy and flexural modulus of the virgin polymer, and this area has received much attention because of these improvements in the physical and mechanical properties of polymers at very low clay loading [1], [2]

The preparation of a nanocomposite may be accomplished either by in situ polymerisation or by blending, with melt blending the industrially preferred process. The most commonly used clays are hydrophilic aluminosilicates, while the majority of polymers are hydrophobic and thus one cannot directly melt blend polymers with the pristine clay. To enhance the interactions between the clay and polymer, the clay must be modified; the usual treatment is to ion-exchange the clay cation for an alkylammonium or phosphonium cation, which contains various substituents, at least one of which must be a carbon chain of 12 carbons or more 3$]$.

In order to obtain a nanocomposite by melt blending, two major factors, compatibility and thermal stability, must be considered. The modified clay must be sufficiently compatible with the polymer and must be thermally stable under the processing conditions. Many of the normal commercially available organically-modified clays begin to undergo thermal degradation near $200^{\circ} \mathrm{C}$ by the Hofmann elimination reaction, which eventually leads to a proton as the counter ion of the clay ${ }^{[4]}$. In this laboratory, significant work has been done to enhance the thermal stability and compatibility of the modified clay by the generation of novel surfactants; these include a stibonium-modified clay ${ }^{[5]}$, a tropylium cation modified clay ${ }^{[6]}$, and various oligomerically-modified clays $[7],[8],[9],[10],[11]$, which exhibit very good thermal stability and show little, if any, degradation below $300{ }^{\circ} \mathrm{C}$.

In this work, nanocomposites of polystyrene, PS, high impact polystyrene, HIPS, acrylonitrile-butadiene-styrene terpolymer, $A B S$, polypropylene, $P P$, and polyethylene, $\mathrm{PE}$, have been prepared and characterized using a methyl methacrylate oligomerically-modified clay by melt blending and the thermal stability and fire retardancy were studied.

\section{Experimental}

\subsection{Materials}

Most of the materials used in this study, including methyl methacrylate, benzoyl peroxide (BPO), inhibitor removal reagent, PS (Melt flow index $200^{\circ} \mathrm{C} / 5 \mathrm{~kg}, 7.5 \mathrm{~g} / 10 \mathrm{~min}, \mathrm{Mw}=230,000$ ), PE (low density, melt flow index, $190^{\circ} \mathrm{C} / 2.16 \mathrm{~kg}, 7 \mathrm{~g} / 10 \mathrm{~min}$ ), $\mathrm{PP}$ (isotactic, melt flow index, $230^{\circ} \mathrm{C} / 2.16 \mathrm{~kg}, 0.5 \mathrm{~g} / 10 \mathrm{~min}$ ), poly(methyl methacrylate), (inherent viscosity $1.250, \mathrm{Mw}=996,000, \mathrm{Tg}=125^{\circ} \mathrm{C}$ ), were acquired from Aldrich Chemical Co. ABS (Magnum 275, $230{ }^{\circ} \mathrm{C} / 3.8 \mathrm{~kg}, 2.6 \mathrm{~g} / 10 \mathrm{~min}$ ) and HIPS (melt flow index $200^{\circ} \mathrm{C} / 5 \mathrm{~kg}, 6 \mathrm{~g} / 10 \mathrm{~min}$ ) were provided by the Dow Chemical Company. The sample of 2-(dimethyaminoethyl) methacrylate was acquired from $\mathrm{TCl}$ America and 1-bromohexadecane was purchased from Lancaster Chemical Company. The sodium montmorollonite was kindly provided by Southern Clay Products, Inc.

\subsection{Instrumentation}

Thermogravimetric analysis (TGA) was performed on an SDT 2960 simultaneous TGA-DTA instrument under a flowing nitrogen atmosphere at a scan rate of $10^{\circ} \mathrm{C} / \mathrm{min}$ from 20 to $600{ }^{\circ} \mathrm{C}$; temperatures are reproducible to $\pm 3{ }^{\circ} \mathrm{C}$, while the error on the fraction of non-volatile material is $\pm 3 \%$. Cone calorimetry was performed using an Atlas Cone 2 instrument according to ASTM E 1354 at an incident flux of $35 \mathrm{~kW} / \mathrm{m}^{2}$ or $50 \mathrm{~kW} / \mathrm{m}^{2}$ using a cone shaped heater. Exhaust flow was set at $24 \mathrm{~L} / \mathrm{s}$ and the spark was continuous until the sample ignited. Cone samples were prepared by compression moulding the sample (20-50 g) into square plaques using a heated press. Typical results from Cone calorimetry are reproducible to within about $\pm 10 \%$. These uncertainties are based on many runs in which thousands of samples have been combusted ${ }^{[12], ~[13]}$. X-ray diffraction was 
performed on a Rigaku Geiger Flex, 2-circle powder diffractometer at a generator tension was $50 \mathrm{kV}$ at a current of $20 \mathrm{~mA}$; scans were take from $2 \vartheta 1.5-10$, step size 0.1, and scan time per step of $10 \mathrm{~s}$. Bright field transmission electron microscopy (TEM) images of the nanocomposites were obtained at $60 \mathrm{kV}$ with a Zeiss $10 \mathrm{c}$ electron microscope. The samples were ultramicrotomed with a diamond knife on Riechert-Jung Ultra-Cut E microtome to give $\sim 70 \mathrm{~nm}$ thick sections. The sections were transferred from the knife-edge to 600 hexagonal mesh $\mathrm{Cu}$ grids. The contrast between the layered silicates and the polymer phase was sufficient for imaging, so no heavy metal staining of sections prior to imaging is required.

\subsection{Preparation of 2-methyacryloyloxyethylhexadecyldimethylammonium bromide}

The preparation of 2-methyacryloyloxyethylhexadecyldimethylammonium bromide was accomplished by a procedure which is similar to that in the literature ${ }^{[14]}$. A $31.4 \mathrm{~g}(0.200 \mathrm{~mol})$ portion of 2-(dimethyaminoethyl) methacrylate and $30.5 \mathrm{~g}(0.100 \mathrm{~mol}) 1$-bromohexadecane were reacted at $50{ }^{\circ} \mathrm{C}$ in the presence of $3000 \mathrm{ppm}$ of the inhibitor hydroquinone monomethyl ether in ethyl acetate for $24 \mathrm{~h}$. After the mixture was cooled to room temperature, the white precipitant was filtered and washed with ethyl acetate, then it was dried in vacuum oven at room temperature for $24 \mathrm{~h}$ and $30.7 \mathrm{~g}$ product was produced. (67\% yield). ${ }^{1} \mathrm{H} \mathrm{NMR}\left(300 \mathrm{MHz}, \mathrm{D}_{2} \mathrm{O}, \delta\right.$, ppm) $\delta 6.13(\mathrm{~s}, 1 \mathrm{H}), 5.57(\mathrm{~s}, 1 \mathrm{H}), 4.59$ (broad, $2 \mathrm{H}), 3.80$ (broad, $2 \mathrm{H}), 3.42$ (broad, $2 \mathrm{H}), 3.21(\mathrm{~s}, 6 \mathrm{H}), 1.85(\mathrm{~s}, 3 \mathrm{H})$, 1.67 (broad, 2H), $1.25(\mathrm{~s}, 26 \mathrm{H}), 0.84(\mathrm{~m}, 3 \mathrm{H})$.

\subsection{Preparation of methyl methacrylate oligomerically-modified clay with $12 \%$ clay loading (PMMA12 clay)}

In a $500 \mathrm{ml}$ 3-neck round bottom flask were placed $9.25 \mathrm{~g}(0.0200 \mathrm{~mol}) 2$ -

methyacryloyloxyethylhexadecyldimethylammonium bromide (MHAB), $100 \mathrm{~g}(1.00 \mathrm{~mol})$ of inhibitor-free methyl methacrylate (MMA), $11 \mathrm{~g}$ benzoyl peroxide (BPO) and $300 \mathrm{ml} \mathrm{CHCl}$. The contents of the flask were stirred until all had dissolved at room temperature under a nitrogen flow, then it was refluxed for $4 \mathrm{~h}$. After this time period, the mixture was quenched by the addition of methanol and the solvent was evaporated at low temperature and pressure. The resulting solid was dissolved in THF, then precipitated by the addition of methanol; $108 \mathrm{~g}$ of a white solid was recovered and the molecular weight was in the range of $3300 \pm 1000$, based on the MarkHouwink constants for poly(methyl methacrylate).

A $16.6 \mathrm{~g}$ sample of the pristine sodium clay in $1000 \mathrm{ml}$ distilled water and $500 \mathrm{ml}$ THF was stirred at room temperature for $24 \mathrm{~h}$. The oligomer prepared above, which was dissolved in $1200 \mathrm{ml}$ of THF in a $2000 \mathrm{ml}$ round bottom flask, was added drop-wise to the dispersed clay; a precipitate appeared immediately and the slurry was stirred at room temperature for $12 \mathrm{~h}$. After the stirring was stopped, the supernatant liquid was poured off and a fresh mixture of $\mathrm{H}_{2} \mathrm{O} / \mathrm{THF}(40 / 60)$ was added and the slurry was stirred again for an additional $12 \mathrm{~h}$ at room temperature. The slurry was filtered and the precipitate was air-dried for one day and then in a vacuum oven at $40{ }^{\circ} \mathrm{C}$ for $48 \mathrm{~h}$ and the modified clay was obtained. The TGA curve of this clay gave a residue of $14 \%$ at $600{ }^{\circ} \mathrm{C}$.

\subsection{Preparation of polymer clay nanocomposites}

All the nanocomposites prepared in this study were melt blended in a Brabender Plasticorder at high speed $\left(60 \mathrm{rmp}\right.$ ) at $190^{\circ} \mathrm{C}$ for $15 \mathrm{~min}$. The composition of each nanocomposite is calculated from the amount of clay and polymer charged to the Brabender.

\subsection{Measurement of molecular weight}

The molecular weights were determined by intrinsic viscosity measurements using the relation $[\eta]=7.0 \times 10^{-3} \mathrm{Mw}^{0.71}$ in toluene at $30^{\circ} \mathrm{C}$. The viscosity average molecular weight of the polymer was $3300 \pm 1000$.

\section{Results and discussion}

A number of oligomerically-modified clays have been prepared in this laboratory and these clays have shown quite different efficiencies in producing nanocomposites with a variety of polymer by melt blending [7], 18], 19], [10], [11]. For example, an oligomerically-modified (styrene modification) clay (COPS clay) can be directly used to prepare exfoliated and intercalated nanocomposite of PS, HIPS, ABS, PE, PP and PMMA by melt 
blending [10], [11], while a methacrylate-modified clay (MAPS clay) did not show compatibility with any of these polymer, including methyl methacrylate ${ }^{[11]}$. In this study, we use 2-

methyacryloyloxyethylhexadecyldimethylammonium bromide and methyl methacrylate copolymer modified clay, herein labelled as PMMA 12 clay. The scheme for the formation of this oligomeric salt is shown in Fig. 1. The aim of this study is to see if the compatibility between a variety polymers and the clay is improved relative to the previous (MAPS) methacrylate-modified clay.

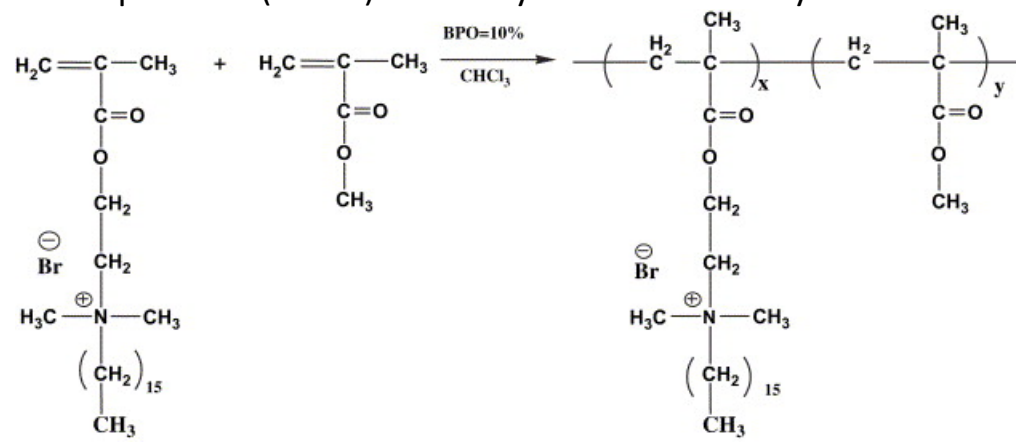

Fig. 1. The reaction route for the formation of the PMMA12 oligomer.

\subsection{X-ray diffraction (XRD) characterization of the nanocomposites}

The changes in the inter-layer spacing of the clay upon the formation of a nanocomposite can be monitored by $X$-ray diffraction, XRD. If one sees a decrease in $2 \vartheta$ this indicates an increase in the $\mathrm{d}$-spacing, which implies the formation of intercalated structure; if no peak can be seen, either a delaminated nanocomposite or a disordered microcomposite can be inferred. Fig. 2, Fig. 3, Fig. 4, Fig. 5, Fig. 6 show the XRD traces for the PMMA12 clay and its nanocomposites. One can clearly see a very broad diffuse peak with the PMMA12 clay, possibly suggesting a mixed intercalated/delaminated structure and no peaks are evident for any of the polymer nanocomposites, which could mean that either a delaminated nanocomposite has been formed or a microcomposite, with a disordered clay structure, is obtained.

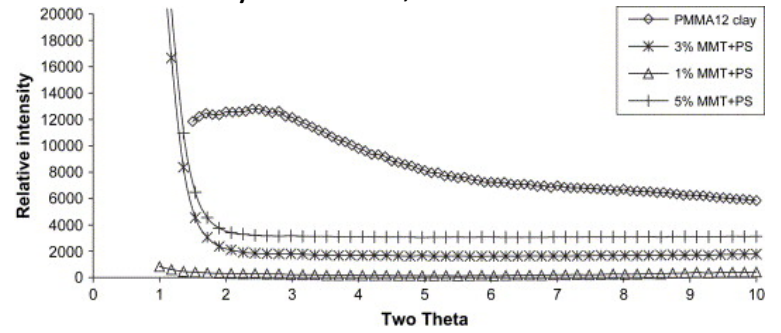

Fig. 2. XRD traces for PMMA12 clay and its PS nanocomposites. The numbers in the legend refer to the amount of inorganic clay that is present.

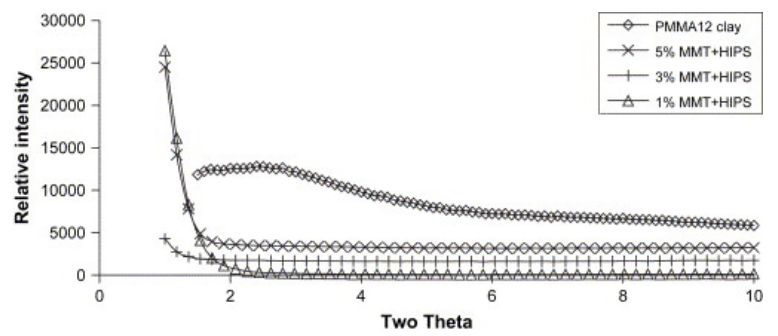

Fig. 3. XRD traces for PMMA12 clay and its HIPS nanocomposites. The numbers in the legend refer to the amount of inorganic clay that is present. 


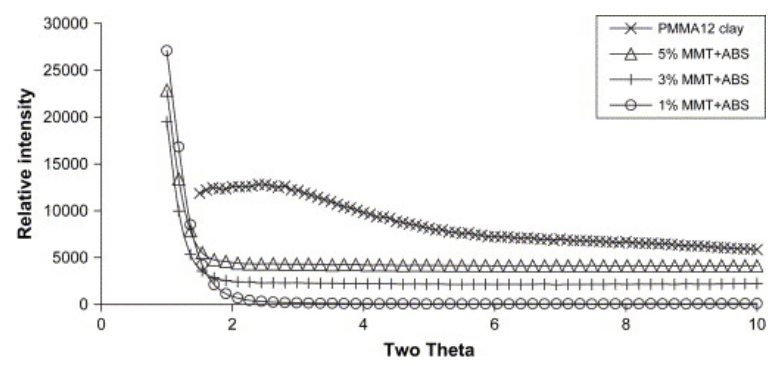

Fig. 4. XRD traces for PMMA12 clay and its ABS nanocomposites. The numbers in the legend refer to the amount of inorganic clay that is present.

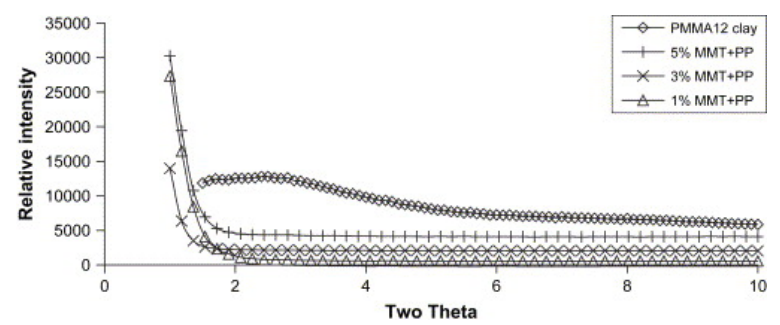

Fig. 5. XRD traces for PMMA12 clay and its PP nanocomposites. The numbers in the legend refer to the amount of inorganic clay that is present.

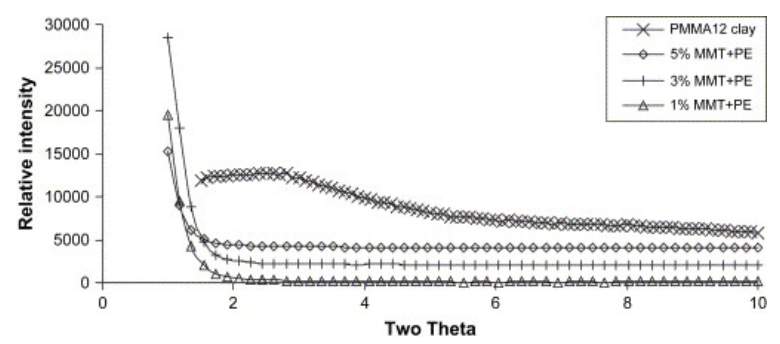

Fig. 6. XRD traces for PMMA12 clay and its PE nanocomposites. The numbers in the legend refer to the amount of inorganic clay that is present.

\subsection{TEM characterization of nanocomposites}

One cannot rely on XRD results alone to determine the type of nanocomposite that has been formed, especially when peaks are absent in XRD traces. In such a case, other techniques must be employed to identify the type of nanocomposite. Transmission electron microscopy, TEM, is the most commonly used technique and it can provide an actual image of the clay layers and permits the determination of the quality of the nano-dispersion (from the low magnification image) and the registry of the clay layers (from the high magnification image). Fig. 7, Fig. 8, Fig. 9, Fig. 10, Fig. 11 show the TEM images for polymer nanocomposite at both low and high magnifications for all systems that have been studied. There is a miscibility problem associated with the combination of PMMA with some of the polymer and this is reflected in the TEM images. The left-hand picture shows the low magnification image and there is good dispersion of the clay in PS and HIPS but this is not found in the cases of ABS, PP or PE, which may be due to the immiscibility of PMMA with these polymers. In the high magnification (on the right-hand side), one can see both tactoids and individual clay layers with polystyrene, while distinct clay layers are nicely distributed and delamination is apparently essentially complete with HIPS. For ABS and PP only tactoids can be seen in the high magnification image while some individual clay layers are apparent in the PE system. It is reasonable to describe the PS nanocomposite as a mixed intercalated/exfoliated nanocomposite, the HIPS nanocomposite as delaminated, ABS and PP as microcomposites and PE as a mixed immiscible/delaminated system. 

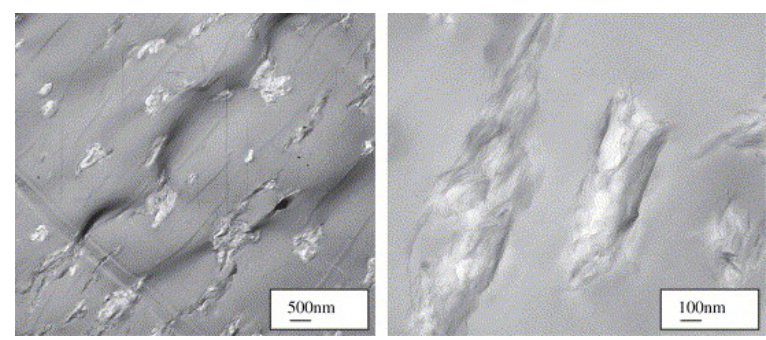

Fig. 7. TEM image at low (left) and high (right) magnification for PS melt blended with PMMA 12 clay (3\% inorganic clay).
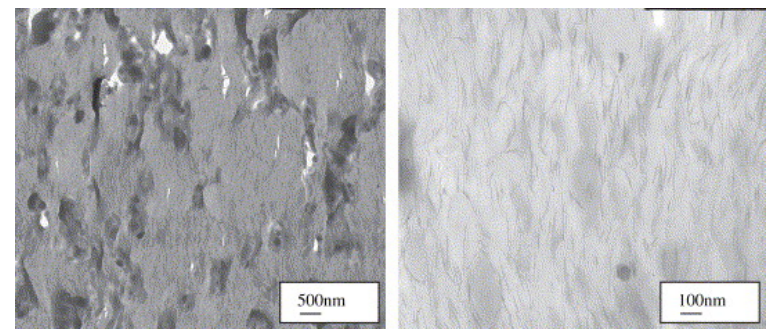

Fig. 8. TEM image at low (left) and high (right) magnification for HIPS melt blended with PMMA 12 clay (3\% inorganic clay).
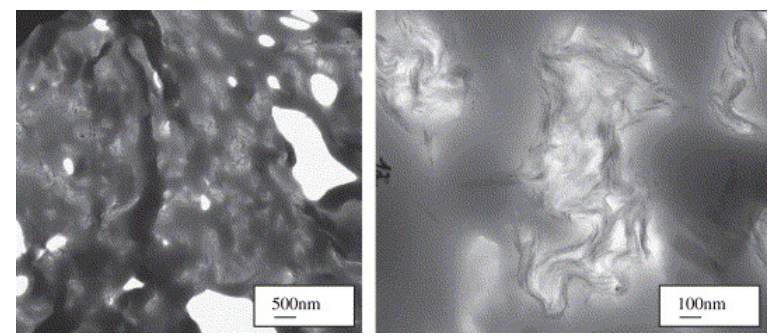

Fig. 9. TEM image at low (left) and high (right) magnification for ABS melt blended with PMMA 12 clay (3\% inorganic clay).
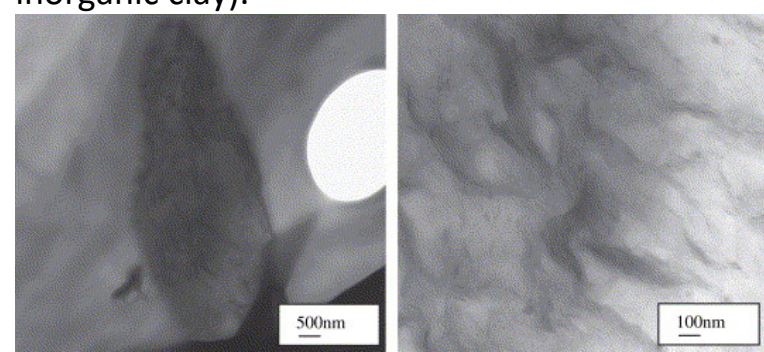

Fig. 10. TEM image at low (left) and high (right) magnification for PP melt blended with PMMA 12 clay (3\% inorganic clay).
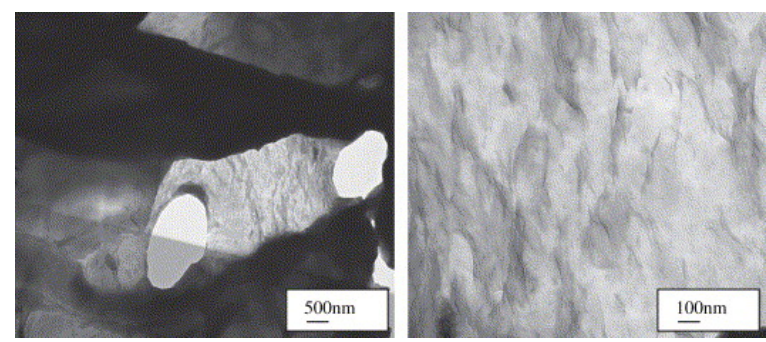

Fig. 11. TEM image at low (left) and high (right) magnification for PE melt blended with PMMA 12 clay (3\% inorganic clay). 


\subsection{Thermogravimetric (TGA) characterization of the nanocomposites}

The thermal stability of the PMMA12 clay and its nanocomposites were evaluated by TGA and the results are shown in Table 1 and Fig. 12, Fig. 13, Fig. 14, Fig. 15, Fig. 16. The data includes the temperature at which 10\% degradation occurs $\left(T_{0.1}\right)$, a measure of the onset temperature of the degradation, the temperature at which $50 \%$ degradation occurs $\left(T_{0.5}\right)$, the mid-point of the degradation process, and the fraction of materials which remains at $600{ }^{\circ} \mathrm{C}$, denoted as char. It is surprising to note that neither the onset temperature nor the mid-point temperature of the degradation is increased by nanocomposite formation, since this is usually observed with styrene nanocomposites. The likely explanation is that the thermal stability of the methacrylate clay itself is not very good and thus it is unlikely that the thermal stability of the nanocomposite can be improved.

Table 1. TGA data for PMMA 12 clay and its nanocomposites

\begin{tabular}{|l|l|l|l|}
\hline & $\begin{array}{l}\boldsymbol{T}_{0.1} \mathbf{(}^{\circ} \\
\mathbf{C})\end{array}$ & $\left.\boldsymbol{T}_{0.5} \mathbf{(}^{\circ} \mathbf{C}\right)$ & Char\% \\
\hline PMMA & 271 & 339 & 0 \\
\hline PMMA12 clay & 279 & 371 & 14 \\
\hline PS & 398 & 426 & 0 \\
\hline 1\% MMT + PS & 382 & 426 & 2 \\
\hline $3 \%$ MMT + PS & 377 & 428 & 4 \\
\hline $5 \%$ MMT + PS & 375 & 424 & 6 \\
\hline ABS & 403 & 431 & 0 \\
\hline $1 \%$ MMT + ABS & 438 & 401 & 2 \\
\hline $3 \%$ MMT + ABS & 388 & 433 & 4 \\
\hline $5 \%$ MMT + ABS & 347 & 422 & 5 \\
\hline HIPS & 425 & 450 & 0 \\
\hline $1 \%$ MMT + HIPS & 402 & 450 & 1 \\
\hline $3 \%$ MMT + HIPS & 388 & 442 & 4 \\
\hline $5 \%$ MMT + HIPS & 377 & 431 & 6 \\
\hline PP & 388 & 440 & 0 \\
\hline $1 \%$ MMT + PP & 384 & 442 & 2 \\
\hline $3 \%$ MMT + PP & 367 & 418 & 4 \\
\hline $5 \%$ MMT + PP & 361 & 423 & 6 \\
\hline PE & 436 & 473 & 0 \\
\hline $1 \%$ MMT + PE & 390 & 469 & 2 \\
\hline $3 \%$ MMT + PE & 381 & 465 & 4 \\
\hline $5 \%$ MMT + PE & 366 & 451 & 6 \\
\hline
\end{tabular}

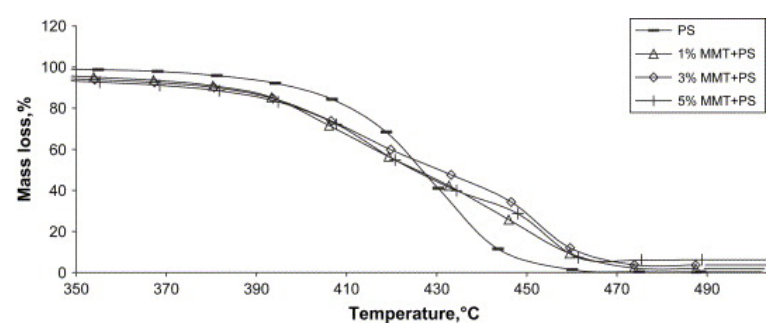

Fig. 12. TGA curve for PMMA 12 clay and its PS nanocomposite. 


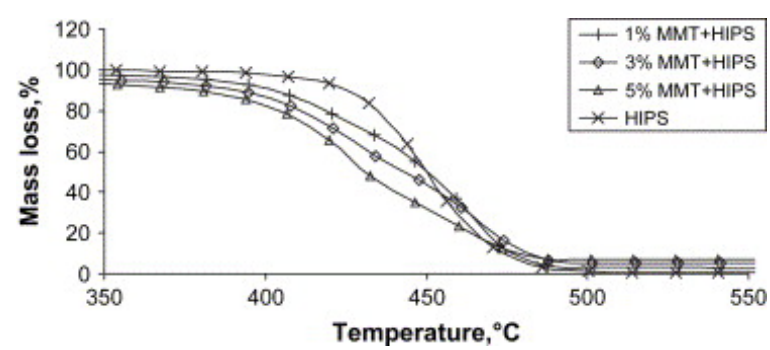

Fig. 13. TGA curve for PMMA 12 clay and its HIPS nanocomposite.

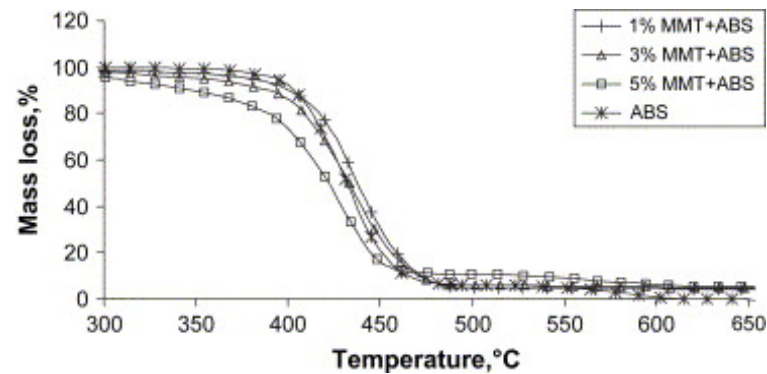

Fig. 14. TGA curve for PMMA 12 clay and its ABS nanocomposite.

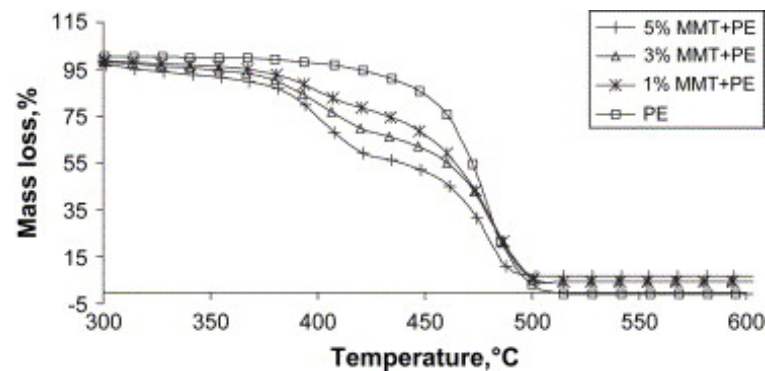

Fig. 15. TGA curve for PMMA 12 clay and its PE nanocomposite.

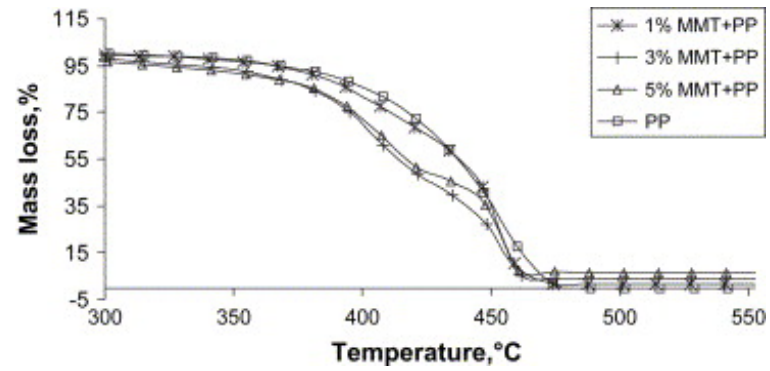

Fig. 16. TGA curve for PMMA 12 clay and its PP nanocomposite.

\subsection{Cone calorimetric characterization of the nanocomposites}

Table 2 and Fig. 17, Fig. 18, Fig. 19, Fig. 20, Fig. 21 show the cone calorimetric results for the polymer clay nanocomposites. The various parameters that are available from cone calorimetry include: the times to ignition, $t_{\text {ign, }}$ and to peak heat release rate, $t_{\text {PHRR; }}$ the heat release rate curve and especially its peak value, PHRR; the specific extinction area, SEA, a measure of smoke; and the mass loss rate, MLR, which usually tracks very well with changes in the PHRR. In previous work from NIST and this laboratory, it has been shown that the rate of heat release is significantly decreased for nanocomposites relative to the virgin polymers and the same reduction is seen whether intercalated or exfoliated nanocomposite are produced while a microcomposite does not show a reduction in PHRR [8], [11]. It is generally considered that the reduction in PHRR must exceed $15 \%$ to be significant and indicate that the system has a nano-dispersed morphology. From the data one can see that there is a substantial reduction in the peak heat release for all polymer systems. As expected the mass loss rate drops and the amount of smoke is slightly increased. Compared with the previous study [10], [11] on MAPS clay nanocomposites, PMMA12 clay nanocomposites show an increased reduction in the peak heat release and 
these values are close to those typically observed for a well-dispersed polymer nanocomposite. This is an indication that very good nano-dispersion throughout the polymer matrix has been achieved by melt blending, even though the TEM results do not show good nano-dispersion in all cases. The problem with the interpretation of TEM data is that it typically represents a snapshot of an extremely small portion of the total material; if this may be assumed to be representative of the whole, then it is a good description. In many cases, a bulk measurement, either some rheological property or cone calorimetry, may give a better indication of the actual morphology of the material.

Table 2. Cone calorimetric data for methacrylate oligomerically-modified clay and its nanocomposites at $35 \mathrm{~kW} / \mathrm{m}^{2}$

\begin{tabular}{|c|c|c|c|c|c|c|}
\hline Sample & $\begin{array}{l}\text { Time to } \\
\text { ignition (s) }\end{array}$ & $\begin{array}{l}\text { PHRR }^{\mathrm{a}} \text {, } \\
\mathrm{kw} / \mathrm{m}^{2} \text { (\% } \\
\text { reduction) }\end{array}$ & $\begin{array}{l}\text { Time to } \\
\text { PHRR (s) }\end{array}$ & $\begin{array}{l}\text { Total heat } \\
\text { released }\left(\mathrm{MJ} / \mathrm{m}^{2}\right)\end{array}$ & $\begin{array}{l}\operatorname{ASEA}\left(m^{2} /\right. \\
k g)\end{array}$ & $\begin{array}{l}\operatorname{MLR}^{\mathrm{a}}(\mathrm{g} / \\
\left.\mathrm{s} \mathrm{m}^{2}\right)\end{array}$ \\
\hline PS & $65 \pm 3$ & $1284 \pm 72$ & $124 \pm 7$ & $98 \pm 4$ & $1146 \pm 36$ & $31 \pm 1$ \\
\hline $1 \% \mathrm{MMT}+\mathrm{PS}$ & $45 \pm 4$ & $1065 \pm 49(17 \%)$ & $133 \pm 2$ & $85 \pm 4$ & $1172 \pm 2$ & $27 \pm 0$ \\
\hline $3 \% \mathrm{MMT}+\mathrm{PS}$ & $40 \pm 2$ & $555 \pm 11(57 \%)$ & $82 \pm 2$ & $76 \pm 5$ & $1155 \pm 30$ & $16 \pm 0$ \\
\hline $5 \% \mathrm{MMT}+\mathrm{PS}$ & $35 \pm 3$ & $378 \pm 20(71 \%)$ & $94 \pm 6$ & $76 \pm 1$ & $1237 \pm 25$ & $11 \pm 1$ \\
\hline HIPS & $72 \pm 4$ & $1235 \pm 29$ & $158 \pm 17$ & $109 \pm 3$ & $1245 \pm 10$ & $29 \pm 0$ \\
\hline $1 \% \mathrm{MMT}+\mathrm{HIPS}$ & $60 \pm 8$ & $1051 \pm 20(15 \%)$ & $142 \pm 7$ & $95 \pm 5$ & $1215 \pm 4$ & $25 \pm 0$ \\
\hline $3 \% \mathrm{MMT}+\mathrm{HIPS}$ & $46 \pm 4$ & $490 \pm 24(60 \%)$ & $125 \pm 10$ & $72 \pm 4$ & $1240 \pm 62$ & $14 \pm 1$ \\
\hline $5 \%$ MMT + HIPS & $52 \pm 4$ & $454 \pm 10(63 \%)$ & $110 \pm 2$ & $77 \pm 1$ & $1184 \pm 21$ & $12 \pm 1$ \\
\hline ABS & $66 \pm 2$ & $1091 \pm 50$ & $138 \pm 4$ & $92 \pm 4$ & $1267 \pm 39$ & $25 \pm 1$ \\
\hline $1 \% \mathrm{MMT}+\mathrm{ABS}$ & $61 \pm 1$ & $889 \pm 47(19 \%)$ & $151 \pm 1$ & $89 \pm 3$ & $1164 \pm 4$ & $21 \pm 0$ \\
\hline $3 \% \mathrm{MMT}+\mathrm{ABS}$ & $53 \pm 2$ & $623 \pm 71(43 \%)$ & $125 \pm 5$ & $77 \pm 5$ & $1117 \pm 20$ & $17 \pm 1$ \\
\hline $5 \% \mathrm{MMT}+\mathrm{ABS}$ & $48 \pm 4$ & $543 \pm 38(50 \%)$ & $116 \pm 10$ & $75 \pm 7$ & $996 \pm 40$ & $15 \pm 1$ \\
\hline $\mathrm{PE}$ & $67 \pm 3$ & $1689 \pm 32$ & $132 \pm 4$ & $112 \pm 3$ & $532 \pm 23$ & $22 \pm 1$ \\
\hline $1 \% \mathrm{MMT}+\mathrm{PE}$ & $50 \pm 1$ & $1391 \pm 13(18 \%)$ & $140 \pm 3$ & $104 \pm 10$ & $571 \pm 11$ & $20 \pm 0$ \\
\hline $3 \% \mathrm{MMT}+\mathrm{PE}$ & $43 \pm 2$ & $1084 \pm 19(36 \%)$ & $161 \pm 14$ & $94 \pm 4$ & $470 \pm 16$ & $17 \pm 1$ \\
\hline $5 \% \mathrm{MMT}+\mathrm{PE}$ & $35 \pm 1$ & $602 \pm 17(64 \%)$ & $124 \pm 6$ & $80 \pm 5$ & $552 \pm 23$ & $11 \pm 1$ \\
\hline PP & $55 \pm 2$ & $1586 \pm 49$ & $131 \pm 7$ & $113 \pm 9$ & $599 \pm 74$ & $20 \pm 1$ \\
\hline $1 \% \mathrm{MMT}+\mathrm{PP}$ & $66 \pm 2$ & $1108 \pm 29(30 \%)$ & $168 \pm 1$ & $104 \pm 1$ & $493 \pm 16$ & $16 \pm 1$ \\
\hline $3 \% \mathrm{MMT}+\mathrm{PP}$ & $44 \pm 1$ & $839 \pm 77(47 \%)$ & $141 \pm 10$ & $87 \pm 3$ & $606 \pm 23$ & $15 \pm 1$ \\
\hline $5 \% \mathrm{MMT}+\mathrm{PP}$ & $35 \pm 1$ & $557 \pm 19(65 \%)$ & $93 \pm 4$ & $77 \pm 6$ & $708 \pm 49$ & $11 \pm 1$ \\
\hline
\end{tabular}

aPHRR, peak heat release rate; \% reduction = [PHRR (virgin polymer)-PHRR (nanocomposite)/PHRR (virgin polymer); ASEA, average specific extinction area; AMLR, average mass loss rate.

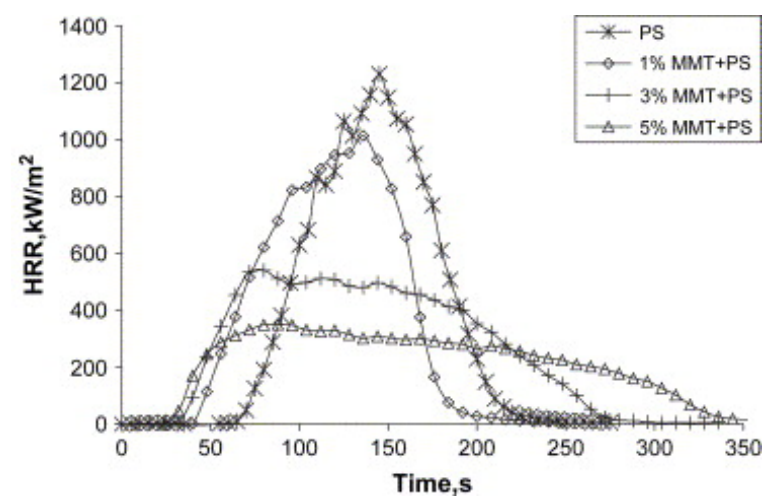

Fig. 17. Heat release rate curves for PS-PMMA12 clay nanocomposites. 


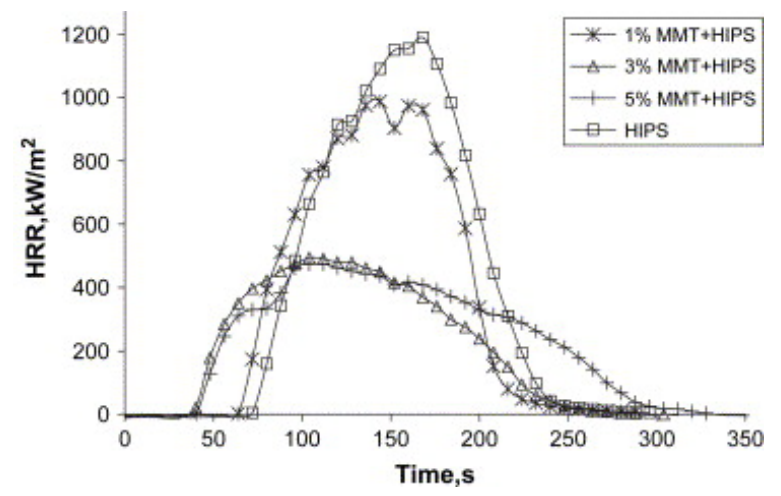

Fig. 18. Heat release rate curves for HIPS-PMMA12 clay nanocomposites.

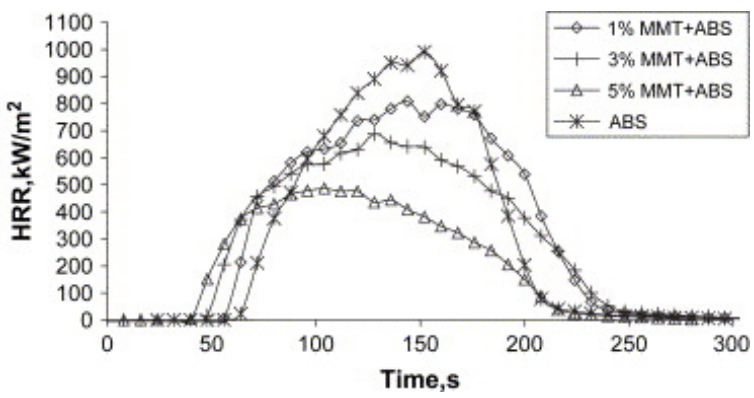

Fig. 19. Heat release rate curves for ABS-PMMA12 clay nanocomposites.

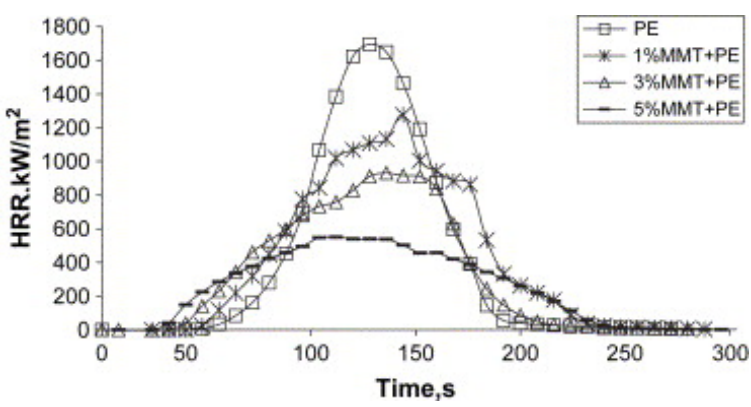

Fig. 20. Heat release rate curves for PE-PMMA12 clay nanocomposites.

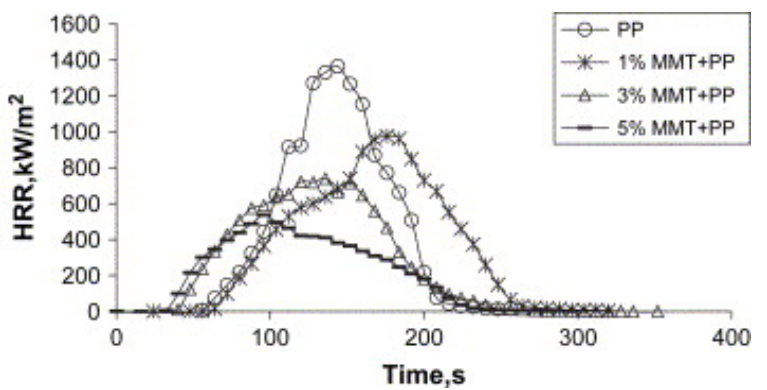

Fig. 21. Heat release rate curves for PP-PMMA12 clay nanocomposites.

\section{Conclusions}

A methyl methacrylate oligomerically-modified clay can be used to prepare nanocomposites of polystyrene and high impact polystyrene but only microcomposites are obtained with ABS, polypropylene and polyethylene, as determined by XRD and TEM. On the other hand, when evaluated by cone calorimetry, the nano-dispersion appears to be very good in all cases, which suggests that the most commonly used combination of XRD and TEM may not be the best way to determine the extent and type of nano-dispersion and suggest that some bulk measurement is needed for this purpose. 


\section{References}

[1]M. Alexandre, P. Dubois. Mater Sci Eng, R28 (2000), pp. 1-63

[2] T. Pinnavaia. J Sci, 220 (1983), pp. 365-371

[3] J. Zhu, C.A. Wilkie. Polym Int, 49 (2000), pp. 1158-1163

[4]J. Zhu, F. Uhl, A.B. Morgan, A.C.A. Wilkie. Chem Mater, 13 (2001), pp. 4649-4654

[5] D. Wang, C.A. Wilkie. Polym Degrad Stab, 82 (2003), pp. 309-315

[6] J. Zhang, C.A. Wilkie. Polym Degrad Stab, 83 (2004), pp. 301-307

[7]S. Su, D.D. Jiang, C.A. Wilkie. Polym Adv Tech, 15 (2004), pp. 225-231

[8] S. Su, D.D. Jiang, C.A. Wilkie. J Vinyl Add Tech, 10 (2004), pp. 44-51

[9]S. Su, D.D. Jiang, C.A. Wilkie. Polym Degrad Stab, 84 (2004), pp. 279-288

[10]S. Su, D.D. Jiang, C.A. Wilkie. Polym Degrad Stab, 83 (2004), pp. 333-346

[11]S. Su, D.D. Jiang, C.A. Wilkie. Polym Degrad Stab, 83 (2004), pp. 321-331

[12] J.W. Gilman, T. Kashiwagi, M. Nyden, J.E.T. Brown, C.L. Jackson, S. Lomakin, et al.. S. AlMalaika, A. Golovoy, C.A. Wilkie (Eds.), Chemistry and technology of polymer additives, Blackwell Scientific (1999), pp. 249-265

[13] J.W. Gilman, T. Kashiwagi, E.P. Giannelis, E. Manias, S. Lomakin, J.D. Lichtenham, et al. M. Le

Bras, G. Camino, S. Bourbigot, R. Delobel (Eds.), Fire retardancy of polymeric materials, the use of intumescence, Royal Society of Chemistry, Cambridge (1998), pp. 203-221

[14] W. Zhang, Y. Liang, W. Luo, Y. Fang. J Polym Sci Polym Chem, 41 (2003), pp. 3218-3226 